\title{
Programação fetal e as consequências no desenvolvimento da progênie - uma revisão
}

\author{
Fetal programming and the consequences on progeny development - a review \\ La programación fetal y las consecuencias en el desarrollo de la progenia - una revisión
}

Recebido: 18/09/2021 | Revisado: 26/09/2021 | Aceito: 28/09/2021 | Publicado: 01/10/2021

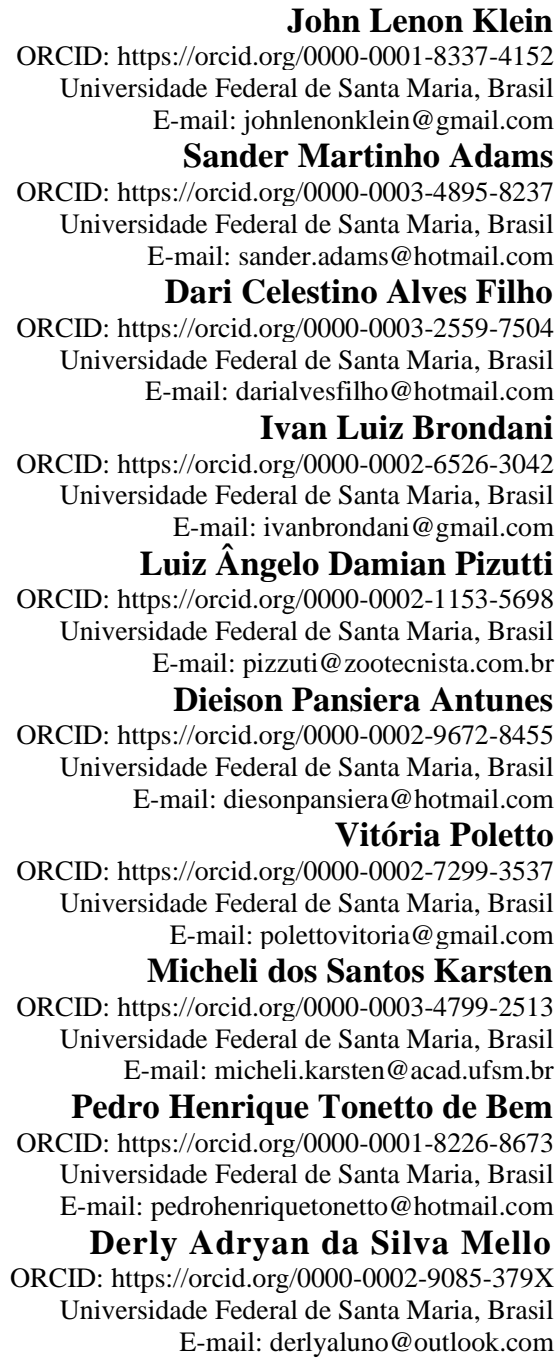

\section{Resumo}

O objetivo deste trabalho foi, através de uma revisão de literatura, identificar as principais alterações fisiológicas e comportamentais causadas pela programação fetal que afetam a saúde e o desempenho da progênie na vida pós-natal. Dentre os inúmeros fatores que alteram a formação fetal, a nutrição materna na gestação tem sido fortemente referenciada nas pesquisas recentes. A nutrição materna na gestação pode alterar de inúmeras formas a formação fetal, de forma que o feto se adapte o mais rapidamente possível ao ambiente uterino, sendo essas mudanças perceptíveis durante a vida adulta da progênie. De modo geral, a literatura sugere que a restrição materna na gestação pode promover mudanças fisiológicas e funcionais nos órgãos e tecidos do feto, preparando o organismo para sobreviver em ambientes desafiadores também na vida pós-natal. Além disso, indivíduos que experimentaram ambientes restritos durante a formação fetal, apresentam maior procura por alimento e comportamentos psicossociais alterados, tais como reações de medo, isolamento e reatividade. A maior eficiência produtiva e consequentemente menor idade de abate da progênie tem sido associada a melhor nutrição materna durante a gestação, uma vez que esses indivíduos possuem formação fetal adequada e, portanto, maior capacidade metabólica dos nutrientes em sistemas intensivos de produção que almejam o máximo desempenho animal.

Palavras-chave: Comportamento animal; Crescimento fetal; Desempenho. 


\begin{abstract}
The objective of this work was, through a literature review, to identify the main physiological and behavioral changes caused by fetal programming that affect the health and performance of the progeny in the postnatal life. Among the numerous factors that alter fetal formation, maternal nutrition during pregnancy has been strongly referenced in recent research. Maternal nutrition during pregnancy can alter fetal formation in numerous ways, so that the fetus adapts as quickly as possible to the uterine environment, and these changes are noticeable during the adult life of the progeny. In general, the literature suggests that maternal restriction during pregnancy can promote physiological and functional changes in fetal organs and tissues, preparing the organism to survive in challenging environments also in postnatal life. In addition, individuals who experienced restricted environments during fetal formation have a greater search for food and altered psychosocial behaviors, such as fear reactions, isolation and reactivity. Higher production efficiency and consequently lower age at slaughter of the progeny has been associated with better maternal nutrition during pregnancy, since these individuals have adequate fetal formation and, therefore, greater metabolic capacity of nutrients in intensive production systems that aim for maximum performance animal.
\end{abstract}

Keywords: Animal behavior; Fetal growth; Performance.

\title{
Resumen
}

El objetivo de este trabajo fue, a través de una revisión de la literatura, identificar los principales cambios fisiológicos y conductuales provocados por la programación fetal que afectan la salud y el desempeño de la progenie en la vida posnatal. Entre los numerosos factores que alteran la formación fetal, la nutrición materna durante el embarazo ha sido fuertemente referenciada en investigaciones recientes. La nutrición materna durante el embarazo puede alterar la formación fetal de muchas formas, de modo que el feto se adapte lo más rápidamente posible al entorno uterino, y estos cambios se notan durante la vida adulta de la progenie. En general, la literatura sugiere que la restricción materna durante el embarazo puede promover cambios fisiológicos y funcionales en los órganos y tejidos fetales, preparando al organismo para sobrevivir en ambientes desafiantes también en la vida postnatal. Además, las personas que experimentaron entornos restringidos durante la formación fetal tienen una mayor búsqueda de alimentos y comportamientos psicosociales alterados, como reacciones de miedo, aislamiento y reactividad. La mayor eficiencia productiva y en consecuencia la menor edad al sacrificio de la progenie se ha asociado a una mejor nutrición materna durante la gestación, ya que estos individuos tienen una adecuada formación fetal y, por tanto, mayor capacidad metabólica de nutrientes en sistemas de producción intensiva que apuntan al máximo rendimiento animal.

Palabras clave: Conducta animal; Crecimiento fetal; Rendimiento.

\section{Introdução}

Avanços recentes na pesquisa sugerem que o potencial produtivo do indivíduo começa a ser definido durante o desenvolvimento intra-uterino. Conceitos conhecidos como programação fetal ou programação do desenvolvimento referem-se aos fatores que afetam o crescimento e desenvolvimento fetal que levam a alterações a longo prazo tanto na estrutura, como na função do órgão (Reynolds \& Caton, 2012). Segundo Castro-Rodríguez et al. (2020), os estudos em animais indicam que as condições subótimas durante a gravidez têm um impacto adverso na saúde materna e fenótipo da prole.

Dentre os diversos insultos que afetam o ambiente uterino durante a gestação, merece destaque a nutrição. Segundo Du et al. (2013), a ingestão de nutrientes pela vaca gestante está associada com a produtividade da prole na vida adulta. Muitos estudos cuidadosamente controlados mostram que virtualmente cada sistema orgânico e função metabólica são afetados pela programação de desenvolvimento em bovinos de corte e outros animais de criação (Reynolds et al., 2019).

Essas mudanças são causadas pela epigenética, que modifica a expressão de genes sem alteração do genoma do indivíduo. As alterações epigenéticas permitem uma rápida adaptação do feto ao ambiente uterino ao qual está sendo desenvolvido (Reynolds et al., 2019). Desta forma, a desnutrição materna na gestação pode causar o desenvolvimento de um fenótipo "econômico" na prole, resultando potencialmente em maior adiposidade e massa muscular reduzida (Mohrhauser et al., 2015). Assim, a resposta em ambientes restritos de nutrientes pode afetar positivamente o desenvolvimento dos animais melhor adaptados e resistentes a essas condições ambientais (Broadhead et al., 2019).

Mesmo com o avanço das pesquisas, os efeitos da programação fetal sobre a formação fetal e posterior desempenho da progênie ainda são incertos. Logo, o objetivo deste trabalho foi, através de uma revisão de literatura, identificar as principais alterações fisiológicas e comportamentais causadas pela programação fetal que afetam a saúde e o desempenho da progênie na vida pós-natal. 


\section{Metodologia}

A revisão de literatura foi desenvolvida para ampliar os conhecimentos sobre os efeitos da nutrição materna na gestação sobre a formação e qualidade dos descendentes. Para tal, foram localizadas publicações científicas disponíveis nas diversas plataformas de pesquisa acadêmica, tais como: Scientific Electronic Library (https://scielo.org); Portal de Periódicos Capes (https://www.periodicos.capes.gov.br); Science Direct (https://www.sciencedirect.com) e Google Scholar (http://scholar.google.com). Os termos de pesquisa utilizados para formação do banco de dados foram: Programação fetal; nutrição materna na gestação; desempenho da progênie. Quanto muito antigos, ou com resultados fora do objetivo da revisão de literatura, os manuscritos foram desconsiderados para utilização.

\section{Programação Fetal e as Consequências na Progênie}

\section{Programação fetal em bovinos de corte}

De maneira geral, a maioria dos bovinos de corte são mantidos sistemas pastoris de produção, e estão sujeitos a mudanças sazonais na disponibilidade de nutrientes (Taylor et al., 2018). Quando a disparidade na oferta de nutrientes ocorre na fase gestacional das vacas, seus efeitos têm sido constantemente relacionados com a formação fetal e consequentemente com o desempenho da progênie na vida adulta. Isso é considerado programação de desenvolvimento: o conceito que o ambiente intra-uterino durante períodos críticos do desenvolvimento fetal afeta a prole ao longo de sua vida (Broadhead et al., 2019). Reynolds \& Caton (2012) complementam que a programação do desenvolvimento, às vezes também conhecida como programação fetal, refere-se aos fatores que afetam o crescimento e o desenvolvimento fetal e levam a alterações a longo prazo tanto na estrutura do órgão (por exemplo, número alterado de néfrons no rim, alteração número ou tamanho das ilhotas pancreáticas, número alterado de miofibras) como na função dos órgãos, ou até mesmo em ambos aspectos.

A nutrição materna durante a gestação merece destaque quando falamos em insultos ao útero grávido. A subnutrição durante a gestação causa condições subótimas ao ambiente uterino materno, o que pode influenciar positiva ou negativamente o desenvolvimento de órgãos e tecidos fetais e levar a impactos ao longo da vida no desempenho da progênie (Broadhead et al., 2019). Por exemplo, Zago et al. (2020) observaram em sua meta-análise, que a progênie de vacas que consumiram energia e proteína acima das exigências de mantença apresentaram maior ganho de peso na terminação, e produziram uma carcaça com maior teor de marmoreio e gordura de cobertura, aspectos apreciados pelos consumidores.

Do mesmo modo que a restrição nutricional afeta a oferta de nutrientes para o feto, o excesso de nutrientes, ou a superalimentação da vaca gestante, também interfere na formação fetal. Os principais efeitos da supernutrição da vaca sobre o feto são distúrbios metabólicos, tais como resistência à insulina (Radunz et al., 2012), a maior expressão de genes responsáveis pela formação de adipócitos no feto e regulação negativa sobre a miogênese (Tong et al., 2009). Em trabalho realizado com ratos de laboratório, Carlin et al. (2013) afirmaram que o excesso de suplementação com gordura para gestantes reduz a metilação do DNA, e deixa consequências negativas na prole, tais como: riscos de obesidade; ganho de peso descontrolado e preferência alimentar por gorduras.

Todas estas alterações na formação fetal estão associadas à adaptação fetal ao ambiente uterino no qual está submetido. Segundo Reynolds et al. (2019), a programação de desenvolvimento e as mudanças resultantes na estrutura, função e expressão gênica dos órgãos servem para permitir ao feto em desenvolvimento se adaptar às pressões de seleção ambiental de uma maneira relativamente rápida, muito mais que a evolução por mutação genética (isto é, seleção natural). Essas alterações são causadas pela epigenética, onde insultos regulam a expressão ou silenciamento dos genes, sem que haja alterações na sequência do DNA do indivíduo. A nutrição materna é um dos fatores que afeta os mecanismos epigenéticos do DNA e metilação de histonas (Mentch \& Locasale, 2016). 
Assim, o organismo do futuro indivíduo é programado para sobreviver em condições semelhantes às enfrentadas no período fetal. Em condições de restrição alimentar durante a gestação, a baixa ingestão nutricional pela mãe vai ser refletida na drenagem de nutrientes ao feto. Nessa situação, pode ocorrer a formação de um fenótipo "econômico", com maior capacidade de adaptação ambiental e preparado para vivenciar ambientes desafiadores na vida pós-natal (Mohrhauser et al., 2015). Porém, dependendo da severidade do desafio nutricional, as vacas se adaptam a falta de nutrientes da dieta e conseguem manter o crescimento fetal, uma vez que a gestação possui prioridade na partição de nutrientes no organismo materno (Bauman \& Currie, 1980). Segundo Prezotto et al. (2016), a perda de escore e peso corporal pode indicar que vacas e fetos têm a capacidade de se adaptar a períodos tanto de restrição, como de realimentação, de forma que alteram o uso da energia na tentativa de aumentar o digestão e utilização de alimentos ou para alterar os requisitos de manutenção para manter o crescimento e desenvolvimento fetal.

A adaptação materna na gestação interfere na resposta da progênie à programação fetal. Dessa forma, os efeitos da nutrição materna na gestação sobre a formação fetal precisam ser mais claramente elucidados, uma vez que apresentam muitas divergências entre os estudos. Do mesmo modo, faz-se necessário maior associação entre os efeitos da programação fetal com a resposta produtiva da progênie na vida adulta, aspecto que poderá refletir em melhor nutrição da fêmea gestante.

\section{Nutrição materna na gestação e a saúde da progênie}

A hipótese que rege a programação do desenvolvimento afirma que mudanças na nutrição fetal e status endócrino podem criar adaptações que afetam permanentemente a estrutura fetal, a fisiologia, o metabolismo e predispõem a prole a doenças metabólicas e endócrinas após o nascimento (LeMaster et al., 2017). Tais alterações, por sua vez, estão associadas ao aumento do risco de várias patologias crônicas, incluindo síndrome metabólica, anormalidades de crescimento e disfunção imune, alterações comportamentais ou cognitivas na prole ao longo de sua vida útil e até nas gerações subsequentes (Reynolds et al., 2019).

Ao testaram diferentes níveis nutricionais durante a gestação (100\% e 60\%), Prezotto et al. (2016) obtiveram maior peso hepático aos 254 dias de gestação nos fetos de vacas que foram realimentadas no segundo e/ou terceiro trimestre de gestação após passarem por restrição nutricional, demonstrando que houve uma compensação no crescimento do fígado quando houve realimentação, uma vez que os órgãos vitais são prioridade dentre os tecidos fetais. Como referenciado anteriormente, estas alterações podem ser atenuadas pela capacidade adaptativa das vacas e do feto durante a vida fetal, como forma de preservar a saúde da prole. Além disso, pode ocorrer crescimento compensatório do feto após o nascimento, devido maior capacidade de adaptação em ambientes desafiadores na criação. Ramírez et al. (2020) observaram que uma restrição nutricional severa pode induzir uma compensação no crescimento da prole bovina, frente as progênies de vacas com nutrição adequada ou restrição moderada na gestação.

Testando diferentes níveis nutricionais nos últimos terços de gestação, Duarte et al. (2013) observaram que filhos de vacas submetidas à restrição nutricional apresentraam compensação na formação do trato digestório da progênie, com aumento tanto no comprimento do intestino delgado, como das vilosidades intestinais. O intestino delgado é um dos principais sítios de digestão e absorção dos nutrientes da dieta em ruminantes e exerce função primordial na transferência de imunidade passiva. Portanto, seu bom desenvolvimento e funcionalidade é de extrema importância. Blecha et al. (1981) revisaram o efeito da restrição de proteínas nos últimos 100 dias de gestação e não encontraram diferença nas concentrações de IgG no sangue e no colostro da vaca quando alimentada com diferentes níveis de proteína. Porém, a absorção de $\operatorname{IgG}$ pelo bezerro após o nascimento foi maior conforme os níveis de proteína na dieta materna, indicando que bezerros de vacas que consomem baixos níveis de a proteína podem ter a transferência de imunidade passiva diminuída. 
A resposta imunológica pode ser reflexo à programação fetal e desafios do feto na gestação. Em estudo com ratos de laboratório, Barouei et al. (2012) observaram que a suplementação materna na gestação com pró-biótico levou a alterações no eixo cérebro-imunológico-intestino induzidos pela separação materna neonatal e/ou estresse de contenção na idade adulta. Os autores obtiveram melhora no ambiente imunológico de animais estressados e maior proteção, em parte, contra distúrbios induzidos por estresse. Em complemento, Castro-Rodríguez et al. (2020) afirmam que a intervenção com pró-bióticos durante a gravidez e a lactação promove saúde intestinal, melhora a imunidade, equilibra a flora intestinal e reduz o risco de obesidade e distúrbios metabólicos nas mães e nos descendentes.

Além de alterações no trato digestório, algumas alterações causadas pela programação fetal nos órgãos que atuam no metabolismo do animal são apresentadas na literatura atual. Segundo Maresca et al. (2018), a disponibilidade de nutrientes durante o desenvolvimento fetal pode alterar o metabolismo da glicose e a secreção de insulina durante o crescimento pósnatal. O provável mecanismo dessa alteração da dinâmica da glicose e da insulina durante um desafio nutricional na gestação é devido à alteração da sensibilidade a insulina e aos estímulos na captação de glicose no tecido.

Em estudo semelhante, LeMaster et al. (2017) observaram que as concentrações de glicose no plasma de bezerros antes da amamentação refletiram os níveis de glicose materna no parto, e foram maiores em bezerros nascidos de vacas com dieta Controle (100\%) em comparação aos nascidos de vacas submetidas a restrição nutricional na gestação. Do mesmo modo, Taylor et al. (2018) avaliaram a restrição nutricional no início da gestação e obtiveram menor nível plasmático de glicose aos 110 dias de gestação no sangue de fetos de mães restritas. Esses resultados demonstram a sensibilidade fetal aos nutrientes da dieta materna, uma vez que a glicose é a principal fonte de substrato utilizada para a formação fetal.

As mudanças no metabolismo da glicose são moduladas sobretudo pela atuação da insulina, hormônio produzido pelo pâncreas e responsável pela captação de glicose pelos tecidos corporais. Washburn et al. (2016) observaram uma redução na massa de células- $\beta$ pancreáticas fetais e aumento na taxa de apoptose das células- $\beta$ em fetos bovinos que foram expostos à restrição de nutrientes maternos na gestação. Em estudo semelhante, McCarty et al. (2020) avaliaram os efeitos da restrição alimentar nos primeiros terços de gestação e obtiveram menor peso pancreático e níveis séricos de insulina em fetos que experimentaram restrição nutricional no segundo trimestre de gestação, frente aos fetos não-restritos ou que passaram por restrição seguida de realimentação. Além disso, os autores observaram uma redução no número de células pancreáticas e aumento na taxa de apoptose das células- $\beta$ pancreáticas em fetos que passaram por restrição nutricional, independente do período gestacional.

Diante disso, os efeitos da restrição nutricional no segundo trimestre de gestação, ou conforme avança o crescimento fetal, parecem ser mais prejudiciais à formação e saúde do feto, uma vez que a vaca é mais desafiada. Testando os efeitos da restrição nutricional (60\%) ou da realimentação (100\%) durante a gestação, Keomanivong et al. (2015) observaram maior atividade pancreática fetal da enzima $\alpha$-amilase nos animais que passaram por restrição nutricional no primeiro e/ou segundo trimestre de gestação e foram posteriormente realimentados. O desenvolvimento pancreático é fundamental para a função endócrina e pode ser prejudicado devido ao crescimento fetal reduzido (McCarty et al., 2020). Os mesmos autores complementam que a perturbação do crescimento e função pancreática pode reduzir as concentrações de insulina e pode levar a retardo de crescimento pós-natal.

Achados recentes também associaram os efeitos da nutrição materna na gestação com a formação e fisiologia hepática. Segundo Symonds et al. (2010), o desfavorecimento do ambiente uterino durante a fase inicial de gestação pode resultar em alterações nos mecanismos homeostáticos do fígado e pâncreas, influenciando a capacidade da progênie em metabolizar os nutrientes. Trabalhando com ratos de laboratório, Bowman et al. (2019) observaram que o jejum materno na gestação aumentou o peso do fígado fetal e o conteúdo de triglicerídeos da placenta, devido à mobilização das reservas corporais materna para satisfazer as exigências fetais. Esses resultados mostram que o jejum materno aumenta a entrega de 
metabólitos lipídicos ao feto, do mesmo modo que modifica a expressão dos genes para potencializar o metabolismo oxidativo mais precocemente na prole.

Os efeitos da nutrição materna na gestação sobre a saúde da prole podem ser duradouros, mas são comumente mais frequentes nos meses iniciais de vida dos descendentes, dependendo da severidade dos insultos intra-uterinos e capacidade de adaptação do bezerros às condições de criação na vida pós-natal. Porém, Larson et al. (2009) observaram um percentual maior de novilhos nascidos de vacas não suplementadas que requerem tratamento pós-desmame para doenças respiratórias ou gastrointestinais em relação a novilhos nascidos de vacas suplementadas, demonstrando que bezerros desafiados durante a gestação possuem maior suscetibilidade a doenças na vida adulta. Estes aspectos que relacionam a saúde e formação fetal com a programação do desenvolvimento tornam-se importantes quando se almeja o máximo desempenho dos animais, onde pequenos detalhes acabam fazendo a diferença, principalmente em sistemas intensivos de produção.

\section{Alterações comportamentais nos descendentes}

O desempenho da progênie na vida pós-natal está fortemente influenciado por alterações comportamentais, sejam relacionadas com as atividades de interação social, ou atividades de consumo alimentar na vida adulta. Trabalhando com ratos de laboratório, Dearden et al. (2020) observaram aumento no consumo de alimento de ratos nascido de mães obesas, ou superalimentadas. Essa resposta comportamental é consequência da formação hipotalâmica em situações de dietas com alta densidade energética, aspecto que altera o controle alimentar da prole antes mesmo do consumo independente de alimentos, ou seja, a progênie de mães obesas aumentou a ingestão de leite no período pré-desmame (Payolla et al., 2016).

Alterações hormonais também ajudam a explicar mudanças comportamentais na progênie. Quando trabalharam com bovinos de corte, LeMaster et al. (2017) obtiveram maiores níveis de leptina e cortisol ao parto nos bezerros nascidos de vacas submetidas à restrição nutricional, frente aos bezerros nascidos de vacas suplementadas na gestação. A leptina é um importante regulador do consumo no organismo, enquanto que os maiores níveis do cortisol podem ser associados ao comportamento de estresse dos animais. Além do maior consumo alimentar, Reynolds et al. (2019) complementam que o maior crescimento descontrolado da prole de vacas superalimentadas ou de mães obesas pode estar associado a maior metilação e expressão de IGF-1 associado à insulina.

Em geral, o excesso de suplementação, assim como a restrição severa de nutrientes, estão associados ao aumento da adiposidade na carcaça dos animais. Wang et al. (2008) observaram aumento na porcentagem de gordura renal na progênie de ovelhas de partos gemelares em relação à prole de parto único. Segundo os autores, esse aumento de gordura pode alterar a regulação do apetite no animal no período pós-natal, causada por mudanças nas secreções endócrinas do tecido adiposo. Esta alteração do apetite e aumento a adiposidade leva a mais distúrbios metabólicos, como a desregulação da insulina e dos níveis de glicose, também observada em ovelhas que foram restritas durante o início da gestação (George et al., 2012).

Avaliando as alterações comportamentais em bovinos de corte, Miguel-Pacheco et al. (2019) relataram que a restrição protéica da dieta materna durante o período pré-concepção (ou seja, 60 dias antes da concepção), aumenta o peso ao nascer da prole e o comportamento de sucção do leite, e comportamento materno de permanecer em pé após o parto. Esses achados podem indicar um mecanismo compensatório pós-parto que suporta a sobrevivência neonatal: aumento no apetite. Além disso, níveis mais baixos de leptina e IGF-1 foram observados na prole após restrição nutricional durante o período de periconcepção em bovinos e ovinos (Micke et al., 2015). Esses metabólitos são importantes no bezerro, visto que a leptina regula o apetite e o gasto de energia, enquanto o IGF-1 promove o crescimento muscular (Sinclair et al., 2016).

Corroborando com os achados anteriores, Kleemann et al. (2015), observaram que cordeiros filhos de mães subnutridas na gestação retornaram mais rápido para suas mães do que aqueles com dietas padrão (100\%) ou elevada (150\%). No entanto, filhos de ovelhas subnutridas, quando isolados, apresentavam reações comportamentais suprimidas, alteração 
comportamental, redução da atividade locomotora e aumento secreção de cortisol aos 4 e 18 meses de idade (Donovan et al., 2013). Em complemento, DeCapo et al. (2019) relataram em sua revisão de literatura que a deficiência de proteína materna e manipulação de ácido graxo exagerada aumentam a resposta de medo na prole, com exposição a ameaças sustentadas induzindo ao desespero comportamental em contato com uma pessoa.

Os efeitos da programação fetal sobre o comportamento ingestivo no período de terminação dos animais de produção ainda são pouco explorados, porém podemos induzir que o comportamento suprimido e maior reatividade da progênie de mães subnutridas na gestação, pode reduzir a ingestação de alimento e consequentemente o desempenho dos animais em sistemas mais intensivos, uma vez que nesses sistemas ocorre uso da suplementação e competição por espaço de cocho. Do mesmo modo, a obesidade materna ou a superalimentação na gestação pode levar a alterações no apetite e busca pelo alimento da prole, que em sistemas produtivos torna-se interessante, desde que esse indivíduo seja capaz de metabolizar os nutrientes da dieta.

\section{Implicações no desempenho da progênie}

De acordo com o apresentado anteriormente, os insultos ao útero grávido provocam alterações fenotípicas no organismo animal, sendo estas alterações necessárias à rápida adaptação do concepto ao ambiente uterino. Contudo, essas mudanças causadas pela epigenética preparam o indivíduo para um ambiente de criação pós-natal semelhante ao vivenciado no período fetal. Assim, a resposta produtiva dos indivíduos aos manejos vai depender muito do sistema de criação e da capacidade de adaptação fisiológicas dos animais.

Estas adaptações fisiológicas determinam a capacidade produtiva da progênie quando desafiados na vida adulta. Por exemplo, Silva et al. (2021) observaram que a suplementação 115 dias antes da concepção melhorou a digestibilidade aparente da fibra do trato digestório e a eficiência alimentar de bezerros de corte com programação fetal. No mesmo experimento, os autores observaram que bezerros cujas mães receberam metionina tenderam a ter maior digestibilidade aparente de FDN e FDA no trato digestório total e menor concentração de glicose no sangue em relação aos bezerros de mães controle e sulementadas com farinha de peixe. Estes dados indicam que o suprimento materno de metionina durante o período de periconcepção desempenha um papel importante na programação do desempenho futuro da prole.

Em estudo semelhante, Cruz et al. (2019) não observaram influência da suplementação com proteína para vacas de corte no meio até o final da gestação sobre a digestibilidade dos nutrientes na prole. Resultados opostos foram obtidos por Relling et al. (2019), os quais observaram que a suplementação de metionina protegida no rúmen para ovelhas durante a gestação aumentou expressão de proteínas de transportadores de aminoácidos intestinais e metilação global do DNA, ou seja, pode contribuir para a maior expressão de genes favoráveis à digestão e aproveitamento dos nutrientes da dieta.

No trabalho de Silva et al. (2021), a melhora na digestibilidade dos componentes da fibra, como referenciado anteriormente, resultou em maior peso de abate, ganho de peso diário e melhorou a eficiência alimentar em novilhos nascidos de vacas suplementadas com de farinha de peixe ou metionina em comparação com novilhos de vacas com dieta controle. Dado que a digestibilidade da fibra foi o nutriente mais afetado no referido estudo, os autores inferem que o microbioma ruminal também pode ser afetado pela dieta materna durante a gestação. Stalker et al. (2006) avaliaram o desempenho da progênie de vacas com suplementação (42\% de PB) em contraste com vacas mantidas em pastagem nativa no final da gestação. Os bezerros de mães suplementadas ganharam mais peso e foram mais pesados ao desmame em comparação com bezerros de vacas não suplementadas. No entanto, o desempenho do confinamento (ganho médio diário, eficiência alimentar e consumo de matéria seca) foi semelhante para ambas as progênies, concluindo que alimentação suplementar para a vaca pode não influenciar o desempenho da progênie após o desmame. 
Do mesmo modo, Larson et al. (2009) demonstraram que a nutrição da mãe afetou os bezerros peso ao nascer e os ganhos de peso nos meses iniciais de vida dos bezerros. Os autores complementam que essa diferença persistiu até o desmame e abate, e que os novilhos de vacas suplementadas tendem a ganhar mais peso após a colocação no confinamento em comparação com novilhos de vacas não suplementadas. Em estudo meta-analítico, Zago et al. (2020) observaram que os novilhos cujas mães consumiram proteína e energia acima dos níveis exigidos durante o terceiro trimestre de gestação foram abatidos 5,5 dias antes em comparação com outros novilhos. Este resultado é reflexo do melhor desempenho da progênie de vacas bem nutridas na gestação, uma vez que conseguem potencializar a utilização de nutrientes em sistemas intensivos de produção.

Como descrito anteriormente, a resposta produtiva da progênie depende da formação dos órgãos e tecidos, os quais vão estar mais adaptados ao ambiente que enfrentaram no período fetal. Estudos têm mostrado que a progênie de vacas que consomem PB acima de suas necessidades, durante o segundo e terceiro trimestres de gestação têm menor sensibilidade à insulina (precisa mais insulina para resposta dos tecidos para captar glicose), aspecto que influencia diretamente a utilização da glicose pelas células, e afeta negativamente o desenvolvimento do corpo (Wilson et al., 2016). Assim, a restrição nutricional na gestação pode levar a sensibilidade à insulina da prole, onde baixos níveis de nutrientes já causam secreção pancreática de insulina, e a resposta dos tecidos na captação de glicose do sangue.

Porém, esses animais poderão apresentar falhas na captação de glicose em dietas ricas em nutrientes na vida adulta, uma vez que o organismo resiste e produz quantidades menores de insulina. Além disso, Vaag et al. (2012) ressaltam em sua revisão de literatura, que os estudos comparativos do baixo peso ao nascer em humanos e ratos desnutridos por proteínas na gestação identificaram mudanças notavelmente na expressão das proteínas-chave de sinalização da insulina e do transportador de glicose GLUT-4 tanto no músculo esquelético, quanto no tecido adiposo. Em complemento, o conteúdo de GLUT-4 foi menor no músculo esquelético de cordeiros cujas mães passaram por restrição alimentar na gestação (Zhu et al. 2006). Os autores afirmam que esses resultados apoiam fortemente o conceito de que o comprometimento do desenvolvimento do músculo esquelético fetal como um resultado da restrição materna precoce predispõe o músculo esquelético da descendência à resistência à insulina.

Desta forma, o real efeito da programação fetal sobre a formação do indivíduo ainda necessita de maiores investigações, uma vez que os resultados são contrastantes devido às variadas adaptações fetais na gestação. Ramirez et al. (2020) não observaram efeitos do nível de energia da dieta materna sobre o consumo de matéria seca e eficiência alimentar da progênie de novilhos progênie. Do mesmo modo, Wilson et al. (2015) não obtiveram diferenças no desempenho e consumo de matéria seca de novilhos nascidos de vacas suplementadas ou não durante a gestação. Trabalhando com baixo e alto nível proteico no final da gestação, Maresca et al. (2019) não observaram mudanças no consumo de alimento, ganho de peso e eficiência alimentar da progênie quando estes foram confinados.

Essa semelhança no desempenho da prole na vida adulta pode ser fruto do ganho compensatório dos animais desafiados na gestação, bem como da formação do fenótipo “econômico”, que em situações mais rústicas de criação podem responder melhor à produtividade. Logo, o sistema de criação pós-natal pode influenciar fortemente os reais efeitos da programação fetal em animais de produção, sendo necessário um número maior de estudos que englobem tanto as mudanças fisiológicas, como suas consequências na produtividade da progênie.

\section{Considerações Finais}

As alterações fenotípicas na formação do fetal são necessárias para uma rápida adaptação do indivíduo ao ambiente uterino. A restrição nutricional durante a gestação apresenta compensação na formação dos órgãos do sistema digestório, como 
uma estratégia para permitir a maior absorção de nutrientes em ambientes restritos na vida adulta. Nessas condições, ocorre aumento na sensibilidade dos tecidos à insulina, favorecendo a captação da glicose do sangue.

A restrição nutricional durante a gestação aumenta a procura e a ingestão de alimento pela prole, como instinto à sobrevivência. Comportamentos de supressão, medo e reatividade também são desenvolvidos pelos animais que experimentaram restrição de nutrientes na gestação.

A suplementação materna na gestação melhora a eficiência produtiva da progênie, principalmente em sistemas intensivos de produção, com maiores ganhos de peso e redução na idade de abate. A progênie possui o organismo preparado para metabolizar maiores quantidades de nutrientes da dieta, uma vez que ocorre maior produção pancreática de insulina e maior número de receptores GLUT-4 nas células alvo para captação da glicose sanguíneas, aspectos que potencializam o desempenho desses animais programados.

\section{Referências}

Barouei, J., Moussavi, M., \& Hodgson, D. M. (2012). Effect of maternal probiotic intervention on HPA axis, immunity and gut microbiota in a rat model of irritable bowel syndrome, Plos One, 7(10), e46051.

Bauman, D. E., \& Currie, B. (1980). Partitioning of nutrients during pregnancy and lactation: a review of mechanisms involving homeostasis e homeorhesis. Journal of Dairy Science, 63(9), 1514-1529.

Blecha, F., Bull, R. C., Olson, D. P., Ross, R. H., \& Curtis, S. (1981). Effects of prepartum protein restriction in the beef cow on immunoglobin content in blood and colostral whey and subsequente immunoglobin absorption by the neonatal calf. Journal of Animal Science, 53(1), 1174-1180.

Bohnert, D. W., Stalker, L. A., Mills, R. R., Nyman, A., Falck, S. J., \& Cooke, R. F. (2013). Late gestation suplementation of beff cows differing in body condition score: Effects on cow and calf performance. Journal of Animal Science, 91(11), 5485-5491.

Bowman, C. E., Alpergin, E. S. S., Cavagnini, K., Smith, D. M., Scafidi, S., \& Wolfgang, M. J. (2019). Maternal lipid metabolism directs fetal liver programming following nutrient stress. Cell Reports, 29(5), 1299-1310.

Broadhead, D., Mulliniks, J. T., \& Funston, R. N. (2019). Development programming in a beef production system. Veterinary Clinics Food Animal, 35(1), 379-390.

Carlin, J., George, R., Reyes, \& T. M. (2013) Methyl donor supplementation blocks the adverse effects of maternal high fat diet on offspring physiology. Plos One, 8(5), e63549, 2013.

Castro-Rodríguez, D. C., Rodríguez-González, G. L., Menjivar, M., \& Zambrano, H. (2020). Maternal interventions to prevent adverse fetal programming outcomes due to maternal malnutrition: Evidence in animal models. Placenta, 102(1), 49-54.

Cruz, W. F. G., Schoonmaker, J. P., Resende, F. D., Siqueira, G. R., Rodrigues, L. M., Zamudio, G. D. R., \& Ladeira, M. M. (2019). Effects of maternal protein supplementation and inclusion of rumen-protected fat in the finishing diet on nutrient digestibility and expression. of intestinal genes in Nellore steers. Animal Science Journal, 90(1), 1200-1211.

Dearden, L., Buller, S., Furigo, I. C., Fernandez-Twinn, D. S., \& Ozanne, S. E. (2020). Maternal obesity causes fetal hypothalamic insulin resistance and disrupts development of hypothalamic feeding pathways. Molecular Metabolism, 42(1), 101079.

DeCapo, M., Thompson, J. R., Dunn, G., \& Sullivan, E. L. (2019). Perinatal nutrition and programmed risk for neuropsychiatric desorders: A focus on animal models. Biological Psychiatry, 85(2), 122-134.

Donovan, E. L. Hernandez, C. E., Matthews, L. R., Oliver, M. H., Jaquiery, A. L., Bloomfield, F. H., \& Harding, J. E. (2013). Periconceptional undernutrition in sheep leads to decreased locomotor activity in a natural environment. Journal of Developmental. Origins of Health and Disease, 4(1), 296-299.

Du, M., Huang, Y., Das, A. K., Yang, Q., Duarte, M. S., Modson, M. V., \& Zhu, M. J. (2013). Manipulating mesenchymal progenitor cell differentiation to optimize performance and carcass value of beef cattle. Journal Animal Science, 91(3), 1419-1427.

Duarte, M. S., Gionbelli, M. P., Paulino, P. V. R., Serão, N. V. L., Martins, T. S., Tótaro, P. I. S., Neves, C. A., Valadares Filho, S. C., Dodson, M. V., Zhu, M., \& Du, M. (2013). Effects of maternal nutrition on development of gastrointestinal tract of bovine fetus at different stages of gestation. Livestock Science, $153,60-65$

George, L. A. Zhang, L., Tuersunjiang, N., Ma, Y., Long, N. M., Uthlaut, A. B., Smith, D. T., Nathanielsz, P. W., \& Ford, S. P. (2012). Early maternal undernutrition programs increased feed intake, altered glucose metabolism and insulin secretion, and liver function in aged female offspring. American Journal of Physiology, 302(1), 795-804.

Keomanivong, F. E., Camacho, L. E., Lemley, C. O., Kuemper, E. A., Yunusova, R. D., Borowicz, P. P., Kirsch, J. D., Vonnahme, K. A., Caton, J. S., \& Swanson, K. C. (2016). Effects of realimentation after nutrient restriction during mid- to late gestation on pancreatic digestive enzymes, serum insulin and glucose levels, and insulin-contating cell cluster morphology. Journal of Animal Physiology and Animal Nutrition, 101(3), 589-604. 
Kleemann, D. O., Kelly, J. M., Rudiger, S. R., McMillen, I. C., Morrison, J. L., Zhang, S., MacLaughlin, S. M., Smith, D. H., Grimson, R. J., Jaensch, K. S., Brien, F. D., Plush, K. S., Hiendleder, S., \& Walker S. K. (2015). Effect of periconceptional nutrition on the growth, behaviour and survival of the neonatal lamb. Animal Reproduction Science, 160(1), 12-22.

Larson, D. M., Martin, J. L., Adams, D. C., \& Funston, R. N. (2009). Winter grazing system and supplementation during late gestation influence performance of beef cows and steer progeny. Journal Animal Science, 87(1), 1147-1155.

LeMaster, C. T., Taylor, R. K., Ricks, R. E., \& Long, N. M. (2017). The effects of late gestation maternal nutrient restriction whit or without protein supplementation on endocrine regulation of newborn and postnatal beef calves. Theriogenology, 87, 64-71.

Maresca, S., Lopes Valiente, S., Rodrigues, A. M., Long, N. M., Pavan, E., \& Quintans, G. (2018). Effect of protein restriction of bovine dams during late gestation on offspring postnatal growth, glucose-insulin metabolism and IGF-1 concentration. Livestock Science, 212, $120-126$.

Maresca, S., López Valiente, S., Rodriguez, A. M., Testa, L. M., Long, N. M., Quintans, G. I., Pavan, E. (2019). The influence of protein restriction during mid- to late gestation on beef offspring growth, carcass characteristic and meat quality. Meat Science, 153, $103-108$.

McCarty, K. J., Washburn, J. L., Taylor, R. K., \& Long, N. M. (2020). The effects of early or mid-gestation nutrient restriction on bovine fetal pancreatic development. Domestic Animal Endocrinology, 70, 1-6.

Mentch, S. J. \& Locasale, J. W. (2016). One carbon metabolism and epigenetics: understanding the specificity. Annals of the New York Academy of Sciences, $1363(1), 91-98$

Micke, G. C., Sullivan, T. M., Kennaway, D. J., Hernadez-Mendrano, J., \& Perry, V. E. A. (2015). Maternal endocrine adaptation throughout pregnancy to nutrient manipulation: consequences for sexually dimorphic programming of thyroid hormones and development of their progeny. Theriogenology, 83(1), 604-615.

Miguel-Pacheco, G. G., Perry, V. E. A., Hernadez-Mendrano, J. H., Wapenaar, W., Keisler, D. H., \& Voigt, J. P. (2019). Low protein intake during the preconception period in beff heifers affects offspring and maternal behaviour. Applied Animal Behaviour Science, 215(1), 1-6.

Mohrhauser, D. A., Taylor, A. R., Underwood, K. R., Pritchard, R. H., Wertz-Lutz, A. E., \& Blair, D. A. (2015b). The influence of maternal energy status during midgestation on beef offspring carcass characteristics and meat quality. Journal of Animal Science, 93, 786-793.

Payolla, T. B., Lemes, S. F., Fante, T., Reginato, A., Silva, G. M., Micheletti, T. O., Rodrigues, H. G., Torsoni, A. S., Milanski, M., \& Torsoni, M. A. (2016). High-fat diet during pregnancy and lactation impairs the cholinergic anti-inflammatory pathway in the liver and white adipose tissue of mouse offspring. Molecular and Cellular Endocrinology, 422(1), 192-202.

Prezotto, L. D., Camacho, L. E., Lemley, C. O., Keomanivong, F. E., Caton, J. S., Vonnahme, K. A., \& Swanson, K. C. (2016). Nutrient restrition and realimentation in beef cows during early and mid-gestation and maternal and fetal hepatic and small intestinal in vitro oxygen consumption. Animal, $10(5)$, $829-837$.

Ramírez, M., Testa, L. M., López Valiente, S., Latorre, M. E., Long, N. M., Rodriguez, A. M., Pavan, E., \& Maresca, S. (2020). Maternal energy status during late gestation: Effects on growth performance, carcass characteristics and meat quality of steers progeny. Meat Science, $164,1-7$.

Radunz, A. E., Fluharty, F. L., Relling, A. E., Fleix, T. L., Shoup, L. M., Zerby, H. N., \& Loerch, S. C. (2012). Prepartum dietary energy source fed to beef cows: II. Effects on progeny postnatal growth, glucose tolerance, and carcass composition. Journal of Animal Science, 90(13), $4962-4974$.

Relling, A. E., Velazquez, M. R., \& Batistel, F. (2019). Maternal supply of polyunsaturated fatty acids and methionine during late-gestation alters amino acid transportes and global DNA methylation in the lamb small intestine. Journal of Animal Science, 97(1), e323.

Reynolds, L. P., \& Caton, J. S. (2012). Role of the pre- and post-natal environment in developmental programming of health and productivity. Molecular and Cellular Endocrinology, 354(1), 54-59.

Reynolds, L. P., Borowicz, P. P., Caton, J. S., Crouse, M. S., Dahlen C. R., \& Ward, A. K. (2019). Developmental Programming of Fetal Growth and Development. Veterinary Clinics Food Animal, 35(2), 229-247.

Silva, G. M. Chalk, C. D., Ranches, J., Schulmeister, T. M., Henry, D. D., DiLorenzo, N., Arthington, J. D., Moriel, P., \& Lancaster, P. A. (2021). Effect of rumen-protected methionine supplementation to beef cows during the periconception period on performance of cows, calves and subsequent offspring. Animal, $15(1), 100055$.

Sinclair, K. D., Rutherford, K. M. D., Wallace, J. M., Brameld, J. M., Stöger, R., Alberio, R., Sweetman, D., Gardner, D. S., Perry, V. E. A., Adam, C. L., Ashworth, C. J., Robinson, J. E., \& Dwyer, C. M. (2016). Epigenetics and developmental programming of welfare and production traits in farm animals. Reproduction and Fertilidad, 28(1), 1443-1478.

Stalker, L. A., Adams, D. C., Klopfenstein, T. J., Feuz, D. M., \& Funston, R. N. (2006). Effects of pre- and postpartum nutrition on reproduction in spring calving cows and calf feedlot performance. Journal of Animal Science, 84(1), 2582-2589.

Symonds, M. E., Sebert, S. P., \& Budge, H. (2010). Nutritional regulation of fetal growth and implications for productive life in ruminants. Animal, 4(7), 1075-1083.

Taylor, R. K., LeMaster, C. T., Mangrun, K. S., Ricks, R. E., \& Long, N. M. (2018). Effects of maternal nutrient restriction during early or mid-gestation without realimentation on maternal physiology and foetal growth and development in beef cattle. Animal, 12(1), 312-321.

Tong, J. F., Yan, X., Zhu, M. J., Ford, S. P., Nathanielsz, P. W., \& Du, M. (2009). Maternal obesity downregulates myogenesis and $\beta$-catenin signaling in fetal skeletal muscle. American Journal of Physiology-Endocrinology and Metabolism, 296(1), e917-e924.

Vaag, A. A., Grunnet, L. G., Arora, G. P., \& Brons, C. (2012). The thrifty phenotype hypothesis revisited. Diabetologia, 55, $2085-2088$. 
Research, Society and Development, v. 10, n. 12, e557101220766, 2021

(CC BY 4.0) | ISSN 2525-3409 | DOI: http://dx.doi.org/10.33448/rsd-v10i12.20766

Zago, D., Canozzi, M. E. A., \& Barcellos, J. O. J. (2020). Pregnant beef cow's nutrition and its effects on postnatal weigth and carcass quality of their progeny. Plos One, 15(8), e0237941.

Zhu, M. J., Ford, S. P., Means, W. J., Hess, B. W., Nathaniels, P. W., \& Du, M. (2006). Maternal nutrient restriction affects properties of skeletal muscle in offspring. The Journal of Physiology, 575(1), 241-250.

Wang, P., Mariman, E., Renes, J., \& Keijer, J. (2008). The secretory function of adipocytes in the physiology of white adipose tissue. Journal of Cell Physiology, 216(1), 3-13.

Washburn, J. L., Taylor, R. K., \& Long, N. M. (2016). The effects of early or mid-gestation nutrient restriction on bovine fetal pancreatic development. Journal of Animal Science, 94(10), 67.

Wilson, T. B., Schroeder, A. R., Ireland, F. A., Faulkner, D. B., \& Shike, D. W. (2015). Effects of late gestation distillers grains supplementation on fallcalving beef cow performance and steer calf growth and carcass characteristics. Journal of Animal Science, 93(1), 4843-4851.

Wilson, T. B., Long, N. M., Faulkner, D. B., \& Shike, D. W. (2016). Influence of excessive dietary protein intake during late gestation on drylot beef cow performance and progeny growth, carcass characteristics, and plasma glucose and insulin concentrations. Journal of Animal Science, 94(1), 2035-2046. 